\title{
EM TORNO DA NOÇÃO DE ANTROPOLOGIA PRIVATIVA, DE RENAUD BARBARAS
}

\author{
Around Renaud Barbaras'notion of privative anthropology
}

En torno a la noción de antropología privada, de Renaud Barbaras

\begin{abstract}
Resumo: Nosso objetivo é abordar a originalidade da filosofia da vida de Renaud Barbaras, a partir da apresentação e discussão de sua noção de antropologia privativa, que, para nós, é o marco decisivo do que viria a ser seu pensamento filosófico, que se completaria com uma cosmologia e uma metafísica. Também abordaremos o ponto de eventual tensão com uma perspectiva fenomenológica, e encerraremos com uma questão sobre sua concepção geral de vida.
\end{abstract}

Palavras-chave: Renaud Barbaras; Fenomenologia, Fenomenologia da vida, Filosofia da vida; Antropologia privativa.

\begin{abstract}
Our goal is to approach the originality of Renaud Barbara's philosophy of life by presenting and discussing his notion of privative anthropology. In our view, that notion is the decisive point of what would become his philosophical thought, which would be completed with a cosmology and a metaphysics. We will also approach what might be a point of tension with a phenomenological perspective and will close with a question on his general concept of life.
\end{abstract}

Keywords: Renaud Barbaras; Phenomenology of life; Philosophy of life; Privative anthropology.

Resumen: Nuestro objetivo es abordar la originalidad de la filosofía de la vida de Renaud Barbaras, a partir de la presentación y discusión de su noción de antropología privativa, que para nosotros es el marco decisivo de lo que vendría a ser su pensamiento filosófico, que se completaría con una cosmología y una metafísica. También abordaremos el punto de eventual tensión con una perspectiva fenomenológica, y encerremos con una cuestión sobre su concepción general de vida.

Palabras clave: Renaud Barbaras; Fenomenología, Fenomenología de la vida, Filosofía de la vida; Antropología privativa.

\section{Introdução}

Cremos que a singularidade do pensamento de Renaud Barbaras se deve a duas razões principais, que o colocam entre os maiores fenomenólogos da atualidade. A primeira delas, é que Barbaras é capaz de discutir o pensamento de um grande número dos principais autores da história da fenomenologia. Barbaras nos brinda em seu percurso filosófico com a apresentação e análise crítica dos pensamentos de Husserl, Heidegger, Hans Jonas, Goldstein, Sartre, Merleau-Ponty, Michel Henry, Erwin Straus, Jan Patočka, Lévinas, Maldiney e Dufrenne. Além da fenomenologia, poderíamos destacar Bergson, Ruyer, acrescentar a psicanálise, da qual se destaca Lacan, e, na poesia, Fernando Pessoa, Rilke e Paul Valéry. Não é pouca coisa, ao contrário, é muita coisa, a ponto de parecer difícil a seus comentadores tecer os fios que formam seu pensamento a partir desse campo tão amplo de leituras que Barbaras utiliza para a realização de sua própria filosofia. Só por essas leituras críticas já seríamos gratos ao seu trabalho, pois de alguma forma aprendemos com essas leituras instigantes ou iluminadoras, independente de concordarmos ou não com algumas de suas passagens ou perspectivas.

Em particular, destaca-se sua recuperação do pensamento de Merleau-Ponty na filosofia contemporânea, a tal ponto que "os estudos sobre Merleau-
-Ponty se dividem em antes e depois de Barbaras" (Moutinho, 2012, p. 63), o que é reconhecido por muitos de seus leitores.

A segunda razão é que toda essa formação por que passou seu pensamento é o solo a partir do qual ele principia e amadurece sua própria filosofia, certamente atento, também, ao pensamento filosófico de nossa época. ${ }^{1} \mathrm{E}$ ele a elaborou de uma forma absolutamente singular e arriscada, e é sobre essa aposta que vamos propor algumas questões a respeito desse pensamento frente ao qual é difícil ficar indiferente.

Dados os limites de nossa apresentação, nosso foco principal será sobre o texto que nos parece inaugurar, de forma fulgurante, a caracterização do que viria a ser sua própria filosofia. Trata-se do ensaio "Vida e consciência", publicado entre nós em 2011 (Barbaras, 2011a), mas que nos foi apresentado em 2007 em uma de suas visitas ao Departamento de Filosofia da UFSCar, ocasião em que pudemos nos deparar propriamente com isso que consideramos que viria a ser o pensamento mais singular de Barbaras, anunciado amplamente, depois, com o lançamento de Introduction à une phénoménologie de la vie (2008). Até então, cremos que nos deparávamos, sobretudo, com a elaboração de 1 Em particular, suas discussões sobre "falta ou privação" e "excesso ou
profusão" como dois polos constitutivos do desejo, parece-nos um diálogo indireto com a crítica de Deleuze à concepção de desejo como falta. 
um pensamento que inovava na leitura crítica dos autores citados, sob a perspectiva de uma filosofia da vida que se esboçava por meio de uma reflexão singular sobre a noção de desejo. Noção de desejo que talvez possa ser destacada como o tema central de sua filosofia. Por outro lado, é digno de nota que já se anunciava, desde o princípio desses trabalhos, cujo marco para nós é Le désir et la distance (1999), a necessidade de uma cosmologia para além da fenomenologia. Como se, embrionariamente, já estivesse tudo lá, isso que por fim se completaria com uma cosmologia e uma metafísica em seus últimos trabalhos, a partir de La dynamique de la manifetation (2013a) até Metaphysique du sentiment (2016a) e Le désir et le monde (2016b).

Ora, qual nos parece a grande aposta de Barbaras nesse ensaio? Simplesmente inverter toda a lógica do pensamento ocidental que vê na realidade humana o que poderíamos precisar, com Hans Jonas, de experiência de maior grau de realidade ontológica do ponto de vista de uma filosofia da vida. Afinal, se uma filosofia da vida é o caminho, segundo Jonas, para a superação dos impasses do dualismo da metafísica moderna - dualismo que nos impede de voltar para trás porque produziu um avanço significativo no campo das ciências objetivas, exigindo, assim, uma síntese superior de outra ordem que aquelas elaboradas no passado da humanidade -, é porque o corpo vivo é a uma só vez extensivo e intensivo, isto é, está entre as coisas e sente - perspectivas de onde partem, respectivamente, o materialismo e o espiritualismo. Em síntese, no homem se encontraria o grau máximo de realidade ontológica, pois nele um corpo se exprime como consciência de si mesmo.

Creio que valha a pena frisar o sentido dessa aposta de Jonas, por meio disso que ele apresenta como uma hipótese, a saber, talvez a mais simples matéria encerre de forma incipiente ou adormecida a sensação ou o afeto que se manifestará de forma mais desenvolvida por meio da experiência da liberdade humana (Jonas, 2004, p. 33). Aposta que reside, pois, na possibilidade de reunião ontológica de toda a realidade em um monismo ontológico, a partir da perspectiva de uma filosofia da vida. $\mathrm{O}$ importante dessa aposta, para os nossos propósitos, não está na defesa do monismo, também defendido por Barbaras em sua crítica a Michel Henry, mas na possibilidade de um grau crescente de realidade ontológica desde a matéria mais simples até a humanidade. Como escreve Jonas (2004),

Num sentido retamente compreendido talvez o ser humano seja a medida de todas as coisas - se bem que não em virtude do seu entendimento mas sim do paradigma de sua totalidade psicofísica, que representa o máximo de completude ontológica concreta que nos é conhecido (p. 32).

Mas Barbaras, como grande conhecedor do pensamento de Jonas, inclusive citando essa mesma passagem (Barbaras, 2003, p. 47), prefere destacar nele o movimento contrário àquele de Heide- gger, que entende a vida a partir da vida do Dasein ou da existência humana, enquanto Jonas procura partir da vida por ela mesma, na qual deve se inscrever as possibilidades da própria humanidade. Mais precisamente, Barbaras, com frequência, critica a zoologia privativa de Heidegger, que significa que a vida animal é a vida humana (ou o mundo humano) menos alguma coisa (o animal é pobre de mundo), contrapondo-a ao movimento da filosofia de Jonas. Como ele diz, em diferentes lugares, Jonas encontra-se a contrapelo do pensamento heideggeriano, cujo Dasein acaba fazendo da humanidade uma exceção entre os seres vivos.

Barbaras reconhece que o antropocentrismo metodológico de Jonas termina por comprometer essa intenção (expressa na ideia de um biocentrismo ontológico), visto que acaba transferindo para o seio da vida as mesmas categorias existenciais de Heidegger, centradas na noção de cuidado (Barbaras, 2008, p. 225). E de modo acentuadamente mais crítico afirma que a opção de Jonas pelo metabolismo como fenômeno primordial da vida, atrelado à ideia de necessidade, por fim não supera sua notória crítica à ontologia da morte, inaugurada na modernidade com a ciência moderna, da qual deriva a própria biologia. Afinal, a vida, para Jonas, consiste no seu embate com a morte, isto é, entre a possibilidade de ser e não ser, decorrente de sua separação do conjunto da realidade, como nascimento de um organismo que busca se manter em vida.

O mais importante aqui, para a nossa questão, é que Barbaras (2003, p. 49) também reconhece que se pode dizer que Jonas procura fundar uma antropologia aditiva, desde que não se veja nessa adição um acréscimo vindo de algo fora da vida. Ele mesmo assumirá essa expressão ("antropologia aditiva”), acompanhando, na ocasião, o pensamento de Jonas frente a Heidegger (Barbaras, 2003, p. 162).

E é por isso que consideramos que mesmo a filosofia da vida de Hans Jonas, por mais importante que seja para Barbaras (2003, p. 43, 2008, p. 205), ainda faz parte de uma longa tradição do pensamento ocidental, segundo a qual o homem é sempre um corpo e mais alguma coisa (razão, espírito, pensamento, consciência ou linguagem).

Podemos lembrar, ao lado de Jonas, A estrutura do comportamento de Merleau-Ponty (2002), com suas diferentes ordens de fenômeno: a física, a vital e a humana, em uma ordem crescente de complexificação de sentidos: a ordem vital assume a ordem física segundo as normas do organismo, e a ordem humana assume a ordem vital segundo a ordem simbólica cultural; de tal forma que a ordem inferior é assumida pela superior, mantendo, entretanto, uma autonomia relativa, que permite falar, segundo Merleau-Ponty, em relação dialética entre as ordens (a integração nunca é completa). Vale frisar que, para Merleau-Ponty a diferença entre as três ordens é funcional, e não substancial: a ordem física pode se expressar em leis, a ordem vital, em normas, e a ordem humana, em símbolos. Mas o importante, aqui, é destacar, mais uma vez na própria fenomenologia, o sentido de uma grande tradição à 
qual pretende se opor Barbaras. ${ }^{2}$

E tal caminho se abriu, para voltar ao ponto inicial de nossa apresentação, com a inversão crítica feita por Barbaras da comparação heideggeriana entre o homem e o animal. Isto é, não é o animal que é visto como diminuído em sua abertura ao Ser em relação ao homem (zoologia privativa), mas, como veremos, é o homem que é a abertura animal ao Ser menos alguma coisa (antropologia privativa).

Nós apresentaremos, pois, o ensaio "Vida e consciência", que nos parece inaugural dessa perspectiva, e concluiremos com algumas questões que, naturalmente, não faltam diante de um pensamento que se choca com uma tradição que parece tão arraigada em nós ou que nos desafia sob uma perspectiva tão contrária à nossa maneira habitual de pensar.

\section{"Vida e consciência"}

Destacaremos oito pontos do ensaio Vida e consciência (Barbaras, 2011a), para a seguir tecermos algumas considerações em torno da noção de antropologia privativa, que se irradiará por toda a filosofia de Barbaras.

1. A afirmação de que a vida sempre foi um problema mal resolvido pela fenomenologia, no sentido de um pressuposto implícito na correlação consciência e mundo, pouco ou não tematizado suficientemente. A mesma objeção de Heidegger a Descartes em Ser e tempo, por este não ter tematizado a fundo o modo de existência do "eu penso", crítica, aliás, lembrada por Barbaras (2011b, p. 52; 2016a, p. 96). Ou, como destaca Riquier (2009) em sua apresentação do trabalho de Barbaras até Introduction à une phénoménologie de la vie (2008), "Descartes se contentava em viver a união, isto é, deixá-la operar nas margens obscuras de seu pensamento, tornando-a acessível unicamente para o sentimento" (p. 982, todas as traduções dos originais franceses são nossas). Em síntese, Barbaras frisa o uso metafórico do conceito de vida na fenomenologia, para expressar essa situação que acusa sua importância de direito, mas não de fato.

2. Para superar tal situação, Barbaras destaca a importância da questão do sujeito para uma fenomenologia da vida, que se mostra, em primeiro lugar, como aquele que faz parte do mundo e para o qual o mundo é ou aparece. Essa é a ambiguidade do próprio termo "viver", que encerra dois sentidos básicos, tanto no francês como no português, isto é, para viver experiências é preciso estar vivo. É a diferença básica entre leben e erleben no alemão, que Merleau-Ponty destacará muito na Fenomenologia da percepção (1945/1994) com as funções anônimas da experiência do corpo próprio, que abrem e possibilitam a vivência de sentidos de mundo e do outro. ${ }^{3}$ Barbaras resume bem esse ponto, dizendo que o sujeito vive no mundo

2 Quase vinte anos depois, Merleau-Ponty (2000, p. 340-341, 353, 426) retomará essa questão, substituindo a relação hierárquica por uma relação lateral entre as ordens. Um cotejo entre a fenomenologia da vida de Barbaras com os cursos de Merleau-Ponty sobre a Natureza nos parece crucial, mas extrapola os limites desse trabalho.

3 A crítica a Merleau-Ponty é crucial para Barbaras. Como ele diz em vários lugares, Merleau-Ponty não teria sido suficientemente radical em direção à elucidação do sujeito da percepção. No caso das funções anônimas do corpo, com Frank Tinland ele afirma "que "essa encarnação do cogito, por mais interessante que seja, vai a par com uma forma de desencarnação do corpo"” (Barbaras, 2003, p. 155). Sobre esse ponto, conferir também Moutinho (2012, p. 64-65) e vive o mundo, ele é essa síntese que uma fenomenologia da vida deve elucidar.

3. A consciência perceptiva, isto é, o viver transitivo (erleben) surge, pois, na vida, no viver intransitivo (leben), e toda a questão é determinar o sentido dessa aparição. E é aqui que Barbaras (2011a) inicia a torsão contrária a toda aquela tradição à qual nos referimos. Ou seja, uma vez que a transitividade deve ser vista como inclusa nas possibilidades da vida (leben) - (“a vida da qual a consciência emerge deve comportar a possibilidade da transitividade desinteressada", p. 165) -, não se pode tomar a consciência perceptiva como algo a mais do que a própria vida. Voltaremos a esse ponto, onde consideramos que se concentra o nó de toda a questão. Por ora, o importante, poderíamos dizer, é não tomar a "consciência da vida" como fora da vida ("o homem não difere da vida: ele difere no seio da vida", Barbaras, 2011a, p. 164). A consciência é ou se dá na própria vida, mas, e esse é o ponto em questão, "a consciência perceptiva pode enraizar-se na vida pois esta, longe de ser limitada ao preenchimento das necessidades, é caracterizada por uma abertura à transcendência, cujo alcance excede muito o da percepção humana" (Barbaras, 2011a, p. 165).

4. E, seguindo a $8^{\text {a }}$. Elegia de Duino, de Rilke (Barbaras, 2011a, p. 166), tal transcendência superior à percepção humana, Barbaras designa de Aberto, na qual vivem os animais, ao menos esses que têm vista, enquanto nós temos o mundo diante dos olhos, mundo que se afasta do Aberto, mantendo-o às suas costas. $\mathrm{O}$ mundo é, nesse sentido, a forma que tomam as coisas quando se afastam da abertura originária do "Ser". Então, ao contrário da zoologia privativa de Heidegger, que acusa a situação de abertura de mundo dos animais como reduzida em comparação com a abertura de mundo do Dasein, Barbaras defende a ideia de uma antropologia privativa, no sentido em que o animal vive uma situação de abertura perceptiva cujo alcance é mais amplo do que essa do homem.

5. Como entender, pois, o surgimento da consciência no seio da vida? Por meio disso que Barbaras chama no ensaio de recalque, repressão, privação ou suspensão do impulso do movimento da vida em direção ao Aberto (2011a, p. 173). Nesse sentido se dá a concepção de antropologia privativa, que é a vida animal menos alguma coisa, pois o animal vive livre no Aberto.

6. Mas, o importante é frisar que o Aberto só é como "negativo" do mundo, mais precisamente, o Aberto é o excesso que se encontra como forro ou diferença pura do mundo. Então, não há mundo sem o Aberto que o suporta ou de onde ele se destaca, mas não há propriamente Aberto sem a presença do mundo, pois o Aberto simplesmente puro só é "imaginável" do ponto de vista ou a partir do mundo, melhor dizendo, o Aberto só pode ser vivido na presença do mundo. Começa aqui, então, a preparação para isso que viria a ser designado em seus últimos trabalhos de "biologia privativa". No ensaio, o foco e a tensão se dão na diferença entre o Aberto da vida animal e o mundo da vida humana, ou entre a vista animal e o olhar humano. Mas, como também destaca Barbaras (2011a, p. 174) no próprio ensaio,

[...] o Aberto, no seio do qual o animal vive, se dá apenas como avesso do mundo que nasce dele, como o invisível que o mundo junta e divide num visível, como aquele fundo sem 
fundo que só a feição do mundo pode sustentar e preservar. É por isso que não há vida pura no Aberto, isto é, uma pura vida animal, pois tal vida seria afinal a negação do Aberto. A vida sempre é vida no mundo, o avanço para o Aberto se depara com a visão de um mundo, por mais simples que seja..

Note-se que, aqui, é o mundo que sustenta o Aberto, afirmação plena de consequências, para nós, porque isso pode se dar de um ponto de vista fenomenológico, até mesmo, no limite, com a inversão dos termos, visto que se pode vislumbrar, também de um ponto de vista estritamente fenomenológico, que o mundo se destaca do Aberto, ou seja, a vida animal e humana surgem no seio do Aberto.

7. Cremos que, dessa forma, Barbaras chega ao fundo de sua própria filosofia, se cabe aqui um trocadilho - afinal, toda filosofia tem um fundo que a caracteriza -; ou chega ao seu umbral, considerando o avanço seguinte de sua filosofia sobre uma cosmologia associada a uma metafísica. Após a indicação de que mesmo o termo "espaço puro" (Munier) corre o risco de certa "objetivação" (o termo é nosso), na medida em que nada ainda está formado (“desenvolvido, desdobrado", 2011a, p. 168), e ressaltando o caráter dinâmico dessa realidade quase "inominável” (o termo é nosso), Barbaras acrescenta: "Além disso, enquanto sítio onde tudo que acontece toma lugar, o Aberto é ao mesmo tempo temporal e, por assim dizer, vivo (grifos nossos). ${ }^{4}$ É preciso concebê-lo dinamicamente como uma potência, a potência de advir que as coisas têm, potência que possibilita seu movimento de advir" (p. 168).

O nome que Barbaras dará a essa potência, a partir de Dynamique de la manifestation (2013a) será o de Arquivida (Archi-vie), mas então dando o passo decisivo a que nos referimos em direção a uma cosmologia para além dos limites de uma fenomenologia. É nesse sentido que consideramos que o ensaio "Vida e consciência", contemporâneo de Introduction à une phénoménologie de la vie (2008), ainda pode ser lido nos limites ${ }^{5}$ de uma fenomenologia:

Mas, enquanto potência nua, que não depende de nada que seja delimitado, o Aberto é apelo puro ou expectativa pura, a iminência de tudo quanto pode ocorrer, ou seja, a iminência como modo de ser [...] elemento do 'há', ele não comporta nenhum limite e, portanto, é aberto para todos os lados, ele é a própria abertura. É também por isso que é preciso entendê-lo como uma potência ou um apelo, e não como um lugar, que nos leva sem pausa nem pontos de referência (Barbaras, 2011a, p. 168-169).

8. Ora, porque em estado de privação ontológica (vida privativa), que outro nome pode-se dar ao sentido da vida dos seres vivos senão esse de seres

4 A temporalidade vai desaparecer no conceito de arquivida em sua cosmologia, que já se anuncia com a característica do Aberto também ser vivo (Barbaras, 2013, p. 189-189, p. 325, 326, 328).

5 Essa também nos parece a avaliação de Pinto (2012, p. 34). desejantes? O modo de ser da vida é, portanto, o desejo. Mesmo o animal vive no e para o Aberto na medida em que tem seu próprio mundo, mundo reduzido em relação ao mundo humano, mas por isso mesmo "mais pleno" porque mais próximo do Aberto. De tal forma que, no caso do humano, tal desejo só pode ser maior ou mais agudo, na medida em que o homem se encontra mais separado do Aberto do que o animal.

De fato, a vista (animal) deixa ser aquilo que ela vê, ao passo que o olhar (humano) é como uma crispação desse "deixar ser”, uma interrupção da acolhida [...]. Tudo nasce desse recuo imperceptível (do olhar), dessa hesitação no seio do "deixar ser", dessa falta de fluidez no êxtase (Barbaras, 2011a, p. 171).

A vista animal encontra-se no Aberto, enquanto o olhar (humano) recua para a formação do mundo: "O mundo é o Aberto quando ele não está mais visto por dentro dele, mas em frente a ele e, na verdade, o mundo é o domínio do "em frente"” (Barbaras, 2011a, p. 170).

Mas, não falamos do amor, com o qual Barbaras encerra o ensaio e também o último trabalho (Le désir et le monde), que a ele se dedica explicitamente. Apenas para registro, pois, dados os limites dessa apresentação, não podemos tratar desse item, aqui, em ambos o amor será apresentado como o meio pelo qual o homem vive, ao menos momentaneamente, a experiência mais bem-sucedida ou possível de sua instalação no Aberto. De modo que o outro pode ser aquele que nos "salva", ou, melhor dizendo, por meio do amor os amantes podem se "salvar", ao menos momentânea ou intermitentemente, do estado de humanidade de privação ou separação da vida, questão à qual se dedicará a metafísica de Renaud Barbaras.

\section{Algumas questões como considerações finais}

Se o leitor, a essa altura se encontra surpreso ou chocado diante dessas proposições, se fomos capazes de expressá-las a contento, a despeito de seu caráter sintético, cremos que esse nos parece um sentimento comum de reação a isso que talvez possamos chamar de um movimento inaugural na filosofia, no sentido de abertura de um novo campo de pensamento. O próprio Barbaras afirma, em um momento de sua obra um pouco mais avançado do que esse do ensaio, que "Chegamos assim a resultados particularmente espantosos" (Barbaras, 2012a, p. 27). Ou ainda, "isso significa, contra toda expectativa, que há mais e não menos vida (nos seres vivos) que na existência humana" (2011b, p. 181, grifos nossos).

De fato, cremos que o encontro com o seu pensamento pode suscitar dois tipos de sentimentos, de preferência conjugados: o de alegria, pela renovação do pensamento ou por uma nova maneira ou possibilidade de olhar a vida - para nós, em particular a dos animais -, e de embaraços, fortes embaraços diante da sua proposta de inversão de nossa maneira habitual de pensar. A tal ponto que, a cada crítica que pensamos fazer ao seu pensamento, fica a suspeita se o que nos falta não é uma conversão mais original de nossa maneira de ver ou pensar o mundo, que igualmente nos implica. A questão da conversão da perspectiva de olhar o mundo ou a vida é plena de senti- 
do filosófico e mesmo científico, se considerarmos, por exemplo, a noção de paradigma em Kuhn. Mas, como não se trata, aqui, de conversão religiosa, cuja operação não passa pela discussão dos conceitos e fatos, como é o caso da filosofia e da ciência, vamos encaminhar algumas questões conceituais a essa proposta de filosofia da vida que, em certo sentido, podemos chamar de paradoxal. ${ }^{6}$

Consideramos que a grande dificuldade em acompanhar o pensamento de Barbaras, que se anuncia com a noção de antropologia privativa, encontra-se na ideia de que a vida animal tem uma abertura ao "Ser" ou Aberto, para usar a terminologia de Barbaras, maior do que a humana. Ou, como vimos, a vida "é caracterizada por uma abertura à transcendência, cujo alcance excede muito o da percepção humana", o que vai a contrapelo do movimento heideggeriano para uma filosofia da vida.

Em outros termos, cremos que a grande dificuldade em concordar com isso se encontra, por um lado, nessa tradição humanista presente ao longo da história do pensamento ocidental, como diz Barbaras, mas também, e esse é o ponto que queremos enfatizar, dado que esse é o nosso ponto de vista, à própria tradição fenomenológica. Como vimos, Barbaras a anuncia no primeiro parágrafo do ensaio. Ou, como ele diz em outro lugar, a vida é o impensado da fenomenologia (Barbaras, 2008, p. 10). Riquier (2013) também se refere a essa dificuldade, comentando, em particular, um texto de Bruce Bégout, no qual este autor mapeia as filosofias da vida presentes na fenomenologia. Em resumo, Bégout identifica a presença de três perspectivas: uma primeira, que se realiza a partir do sentimento interno da vida, que coloca a afetividade em primeiro plano - na qual se destacam Michel Henry e Max Scheler; uma secunda, fundada na expressividade, que privilegia a manifestação da vida no mundo - na qual se destacam Dilthey, Simmel, Husserl e o primeiro Heidegger; e uma terceira, na qual se destacam Jonas e Barbaras, que propõe ultrapassar a oscilação entre as duas anteriores, recuando para aquém da correlação fenomenológica que ambas expressam, a primeira sob a ênfase do primeiro termo da correlação, e a segunda sob a ênfase do segundo termo da correlação (Riquier, 2013, p. 227-228). A crítica de Riquier é que Bégout desconsidera muito rapidamente a terceira opção, tomada por ele como suspeita ou um mal caminho de volta para a metafísica. Mais precisamente, Bégout trata as três possibilidades a partir da fenomenologia husserliana que estabelece a correlação (consciência e mundo) como o limite último da fenomenologia, e assim, diz Riquier, o jogo está decidido antes de ser jogado.

Em contrapartida, para os leitores de Bergson parece mais fácil acompanhar e aceitar a filosofia de Barbaras, dado esse recuo para uma instância anterior à correlação fenomenológica, à qual, como Barbaras diz em mais de um lugar, ele teria sido levado pela própria exigência fenomenológica de elucidação da correlação. Mais ainda, ao lado de Patočka (Barbaras, 2011b, p. 150), Bergson é um

\footnotetext{
6 Barbaras faz uso com frequência de termos paradoxais para expressar seu pensamento, invertendo a tradição ou reunindo o que a tradição costuma separar, o que não é incomum encontrarmos na fenomenologia, de modo geral, a começar pela crítica da atitude natural. Mas, cremos que a inversão que Barbaras opera a partir do conceito de antropologia privativa vai além desses paradoxos, na medida em que ultrapassa a correlação fenomenológica, o que fica claro em sua metafísica, com a tese de que a morte se encontra atrás de nós e não à frente (Heidegger): há uma morte metafísica (anônima) que é a "separação" dos seres vivos da arquivida; morte que significa o nascimento dos seres vivos, dos quais a morte empírica significa o retorno para a Vida (arquivida).
}

dos autores destacados por Barbaras para o seu movimento em direção à cosmologia. ${ }^{7}$

De fato, Riquier é leitor de Bergson, e também procura valorizar essa ultrapassagem interna da fenomenologia no pensamento de Barbaras (Riquier, 2009). Mas isso também fica claro, mais próximo de nós, com Pinto (2012), que destaca o encontro da fenomenologia de Barbaras com Bergson, mas também nomeia a dificuldade da fenomenologia em aceitá-la, ou seja, por um lado se dá "a convergência entre a redução bergsoniana e a redução fenomenológica", e, por outro, a diferença "na questão da finitude, constitutiva e definitiva para a fenomenologia, suscetível de superação, para Bergson" (p. 54) e, podemos acrescentar, para Barbaras.

Da mesma forma nos parece esclarecedor o testemunho de Barbaras (2011c) sobre a sua recepção da obra de Bento Prado Júnior sobre Bergson. ${ }^{8}$ A considerá-lo, devemos incluir Bento entre os principais filósofos, daqueles citados anteriormente, que marcaram a formação de sua filosofia da vida.

Como não abordamos, aqui, a cosmologia e a metafísica presentes nas últimas obras de Barbaras, vamos propor algumas questões, tentando nos manter ao máximo nos limites da fenomenologia, mas sem deixar de indicar as consequências da noção de antropologia privativa para uma cosmologia e uma metafísica em sua filosofia, porque é sobre esse passo que deixaremos uma questão final

Vamos começar com aquele ponto sobre o qual prometemos que voltaríamos, no item 3 de nossa apresentação do ensaio, e que diz que a transitividade deve ser vista como inclusa nas possibilidades da vida (leben) - ("a vida da qual a consciência emerge deve comportar a possibilidade da transitividade desinteressada", Barbaras, 2011a, p. 165) -, e que não se pode tomar a consciência perceptiva como algo a mais do que a própria vida. Em certo sentido, de um ponto de vista natural (contrário ao sobrenatural), essa afirmação parece um truísmo. O imbróglio está no termo "possibilidade". São muitas as dificuldades e nuances da questão, e que, para nós, passa pela questão do negativo em sua filosofia. Vamos iniciá-la, aproveitando a apresentação de Barbaras do conceito de negativo na filosofia na filosofia de Merleau-Ponty, que nos parece notável a partir de sua relação com as concepções do negativo em Husserl e Heidegger.

Conforme Barbaras, o conceito de negativo em Merleau-Ponty se encontra na dimensão da profundidade na percepção de qualquer coisa como um apelo para a sua experiência ou investigação - o que consideramos que remete à ideia de ontologia indireta em Merleau-Ponty, diante disso que o autor chamaria de tentativa e fracasso de uma ontologia direta em Heidegger, isto é, da impossibilidade de dizer o Ser diretamente, o que teria levado Heidegger a certo "mutismo" (a expressão é nossa) em sua filosofia ou às dificuldades de sua expressão (Merleau-Ponty, 1996, p. 147-148).

Barbaras vincula essa perspectiva em Merleau-Ponty à exploração da concepção husserliana de percepção como percepção por perfis, à qual Barbaras também se

$7 \quad$ A própria ideia de antropologia privativa, que considera a percepção humana como uma limitação diante do Aberto e, mesmo depois, a ideia de biologia privativa, que completa a ideia de que a vida perceptiva, em geral, representa uma limitação diante da totalidade do Ser que se abre, apoia-se, em parte, na teoria das imagens e da evolução da vida em Bergson (Barbaras, 1999, p. 150; 2003, p. 183; 2011b, p. 164ss).

8 Trata-se de Presença e campo transcendental, consciência e negatividade na filosofia de Bergson (Bento Prado Júnior, 1989, Edusp). 
filia. Em contrapartida, Husserl teria sido levado, segundo Barbaras, pelo ideal de presença da coisa na percepção, mais precisamente, sua intuição ou adequação à intenção da consciência, concepção que acaba se sobrepondo à da percepção por perfis, cujo destaque é a distância, diferença, incompletude ou ausência e não a proximidade, completude, identidade ou presença da coisa na percepção. Segundo Barbaras, Husserl seria, assim, ainda tributário de uma concepção racionalista e objetiva de mundo. ${ }^{9}$ Feitas tais considerações, citemos a passagem sobre a questão do negativo à qual nos referimos:

A transcendência perceptiva (em Merleau-Ponty) se distingue, portanto, da retirada heideggeriana nisso que ela comporta um apelo a reunir-se a ela, que ela torna possível e mesmo suscita uma progressão, enquanto em Heidegger, bem entendido, não há via do ente ao ser, ou, antes, o ente não contém via em direção ao seu ser. Em uma palavra, em Merleau-Ponty a ausência se figura no visível sob a forma de um recuo indefinido, enquanto ela só é em Heidegger a condição infigurável. Com este, é preciso que eu aceda ao Ser como não-ente para que o ente apareça; em Merleau-Ponty, ao contrário, o percebido só aparece recuando na profundidade, cavando-se nele mesmo, de tal modo que ele é por assim dizer o emblema de sua própria negação, ou antes de sua profundidade (Barbaras, 2011b, p. 85).

\section{Para então completar:}

Aparece aqui uma figura do negativo absolutamente original, à medida da radicalidade da concepção merleau-pontyana da percepção. Em Husserl, o negativo se reduzia a uma negação simples como limitação do positivo, quer dizer, no fundo, como determinação; em Heidegger, o negativo sendo ao contrário referido a esse nada, esse não-ente no qual mergulha o ente enquanto ele é. Poderíamos dizer que o negativo é nos dois casos perdido, por falta em Husserl e por excesso em Heidegger, pois pensá-lo como nada é ainda, como Merleau-Ponty mostrou, ser prisioneiro de uma ontologia da positividade [...]. Desde então, a única maneira de pensar o negativo, isto é, de preservá-lo em sua negatividade, é pensá-lo como distância ou diferença” (Barbaras, 2011b, p. 85).

Como destaca Pinto (2012, p. 59), esse também seria o lugar do negativo no próprio Barbaras. ${ }^{10}$ Mais precisamente, negativo como diferença pura que representa o movimento da vida em direção ao mundo por meio dos entes. Por isso, no ensaio, o mundo é a presença do campo perceptivo que anuncia e 9 Conferir, nesse sentido, o breve, mas luminoso artigo de Sacrini (2012). Veríssimo (2013) sintetiza a contraposição de Barbaras a essa perspectiva da filosofia de Husserl no resumo e no belo título de seu artigo, "A dinâmica pulsional do sensível, Elaborações acerca da percepção em Renaud Barbaras".

10 Mas não cremos que o estatuto do negativo seja o mesmo, questão que nos remeteria à concepção de vida nos dois autores, o que ultrapassa os limites desse artigo. traz o Aberto como diferença pura do mundo visado pelo desejo da percepção. Mas o mundo como englobante inapresentável também faz as vezes do Aberto, em outros textos de Barbaras.

Por exemplo:

Correlativamente, esse mundo não aparece jamais ele mesmo - seria preciso então colocar um outro mundo no qual ele se inscreve: ele é implicado na aparição como o Englobante absoluto, quer dizer, como isso que não aparece como tal. Ele só se apresenta como inapresentável, ele é o invisível, no sentido em que o entendia Merleau-Ponty, isso que é constitutivo do visível (Barbaras, 2003, p. 122).

\section{Ou ainda:}

Esse nada de ente, esse não-intuitivo originariamente dado como subjacente a toda aparição existe necessariamente sobre o modo de uma transcendência pura sem conteúdo próprio, de um excesso que não implica nenhuma alteridade, logo, de uma diferença nua, que é 'diferença de idênticos' (nota MP, VI). É como se o conjunto de entes fosse originariamente e incoativamente diferenciado de si mesmo, em um tipo de grau zero de diferença, para se fazer sua própria condição, se envolver ele mesmo, quer dizer, se transformar em totalidade omni-englobante e aberta (Barbaras, 2011b, p. 200).

Tudo isso assumido, naturalmente, sob a perspectiva de sua filosofia da vida, elaborada a partir da noção de desejo. Em síntese, para Barbaras, o desejo é sempre o excesso presente em toda percepção ou na percepção de qualquer coisa. Excesso puro, sem objeto ou algo que possa preenchê-lo porque é desejo de nada (determinado), ou porque é desejo indeterminado que, no fundo, conforme sua metafísica, é o desejo de outra vida da qual a vida do ser vivo se privou. Ou ainda, o desejo atesta o estado de privação de vida. Não privação da vida, o que seria uma contradição em termos, mas a presença de uma falta no seio da vida do ser vivo, falta que é ao mesmo tempo movimento em direção à plenitude da vida anunciada no Aberto perdido e reconhecido no mundo, no caso da humanidade.

Façamos um movimento paralelo a esse, para nos aproximarmos por outra via da opção de Barbaras por uma antropologia privativa. Cremos que a encontramos em um ponto muito específico e determinante numa leitura que ele faz do estatuto da consciência na correlação fenomenológica. A saber, Barbaras destaca a importância de se precisar o sentido da consciência como, a uma só vez, movimento em direção ao mundo ou, simplesmente, intencionalidade, e consciência de si como movimento. $\mathrm{Ou}$ seja, a consciência é intencional, mas ao mesmo tempo se sabe intencional, do contrário, "espatifar-se-ia no mundo”, como diz Barbaras (2011d, p. 181) com Merleau-Ponty. A questão é não separar esse saber de si do si desse movimento, ou como 
apreendê-los juntos, numa unidade inseparável, mantendo sua diferença. Ora, como diz Barbaras de maneira notável, se pressupomos a intencionalidade como partindo da consciência, então a consciência, como diferença, será sempre um nada separado do mundo ou do que quer que seja, inclusive da vida, objeto de nossa questão. Mas, ao contrário, se pressupomos a consciência como partindo da intencionalidade, então tudo se resolve, porque a intencionalidade é movimento da vida, do qual a consciência aparece como sua negação, como diferença pura ou privação (como recalque do movimento intencional da vida animal, nos termos do ensaio). E assim tudo se encaixa ou se explica na sua concepção da consciência como negação da vida, sem, no entanto, separar-se dela. Ou, ainda, sem ser maior ou a mais do que ela, visto que ela é menos da vida que ela ocupa como sua negação.

Em síntese, o argumento de Barbaras é que, se há consciência perceptiva humana, ela é precedida de uma vida que se manifesta, em sua filosofia, primeiro com a intencionalidade animal, cuja capacidade de transcendência é superior à humana (voltaremos ao ponto), e, depois, como hipervida cosmológica, pura potência de manifestação de mundo que, frisemos, não chega a assumir propriamente um caráter positivo na sua filosofia. Em suas palavras, "uma cosmologia que poderíamos qualificar de negativa” (2003, p. 176). É quase um pressuposto cosmológico à luz de nossa própria experiência da potência de manifestação do mundo, que o movimento regressivo da fenomenologia de Barbaras (2016b, p. 181) procura trazer à lume. Aristóteles expressou tal potência com o termo physis, assim como os antigos, conforme Jonas (2004), antes da entrada da ontologia da morte com a modernidade, viviam-na por meio da experiência do panvitalismo, isto é, viam vida em tudo ou tudo como fazendo parte de um sistema vivo. O que significa, em síntese, "que nossa vida provém de uma vida que nos antecede" (Barbaras, 2012a, p. 26). Em suas palavras:

[...] é melhor dizer que a vida não começou, que ela é caracterizada por uma forma de eternidade que não é outra do que a do arquimovimento de mundificação, sendo que a vida confunde-se com esse arquimovimento. $\mathrm{O}$ processo de mundificação é o sentido primeiro e único da vida. É uma vida que ainda não é a vida de ninguém, uma vida anônima cujo único sujeito é o próprio mundo e que junta, de acordo com o próprio sentido da vida, uma autorrealização e uma fenomenalização: ela é a vida da manifestação. Qualquer vida é da alçada dessa vida originária ou arquivida, o que equivale a dizer que a vida dos seres vivos é mais profunda e mais antiga do que eles mesmos, vem de mais longe do que os próprios seres vivos: estes são apenas realizações ou cristalizações da arquivida (Barbaras, 2012a, p. 26).

Contornando a tese do surgimento da vida no seio da não vida (que nos parece a tese de Merleau-Ponty, da qual não podemos nos ocupar aqui $)^{11}$, ou, mais precisamente, enfatizando, em mais de um lugar, a dificuldade de se compreender a possibilidade da passagem do que não tem vida para a vida dos seres vivos - passagem misteriosa, visto que supõe o surgimento de uma faculdade cuja potência não se apoia na realidade que a antecede, o que se aplica também à consciência -, Barbaras defende que todo movimento é sempre vital, seja o movimento do mundo como manifestação da vida que nos antecede (que é potência pura), seja o movimento que define a especificidade do próprio ser vivo, nesse caso como perda de potência ou algo a menos e não a mais (o que seria misterioso) do que a vida que o antecede.

E assim passamos para a nossa questão propriamente dita, com a qual precisamos avançar sobre as consequências da noção de antropologia privativa para uma cosmologia e uma metafísica na filosofia de Barbaras.

Primeiramente, vale frisar que ela se refere mais ao conteúdo do significado ontológico do termo "antropologia privativa" do que à sua própria letra, na qual o jogo entre o mais e o menos (privação ou adição em relação à vida animal) depende do sentido conferido ao termo em cada situação. E o que leva, por fim, Barbaras (2013a) a reconsiderá-lo, em uma passagem que gostaríamos de citar quase na íntegra, apesar de longa, para fins de clareza da questão, e também por sua beleza. Escreve ele:

Com efeito, ao homem falta isso que possui o animal, a saber, uma aptidão para penetrar dinamicamente no mundo e a se juntar, assim, ao mundo mesmo: ele permanece à distância, em uma relação de face a face que é à exata medida de sua impotência. Entretanto, a importância dessa antropologia privativa é limitada porque ela só tem sentido com a condição de privilegiar o ponto de vista animal, fazendo de seu modo de ser este da própria vida, de seu viver, a vida por excelência. Procedendo assim, esquecemos a metade da verdade nos atendo a um ponto de vista cosmológico, quer dizer, recusando à vida do ser vivo toda dimensão de separação ou de exílio, logo, ignorando a dimensão metafísica do arquiacontecimento. Ora, como mostramos, é antes do lado da cisão, pela qual a arquivida se perde a si mesma ou cai fora dela mesma, que é preciso buscar a razão e o modo de ser dos seres vivos. Segue-se que o homem e o animal se encontram em uma situação simétrica ou equivalente [...]. Seria, pois, absolutamente também legítimo falar de zoologia privativa para significar que o animal é privado disso que o homem possui como próprio, a saber, a situação de exílio, de separação radical com o mundo. Cada um é privado disso que o outro possui, ou, antes, cada um possui eminentemente isso que o outro só possui de maneira parcial e derivada [...]. Nesse sentido, o homem seria o ser vivo por excelência, enquanto o animal se contenta, por assim dizer, de viver, na medida em que ele é ainda tomado na vida anônima

11 Merleau-Ponty chega à concepção da carne do mundo, que é o sensível e não o objeto da ciência, mas não postula seu sentido como animado e produzido pela vida do mundo ou do próprio Ser. 
do mundo, conserva uma inscrição na obscuridade da arquivida (grifo nosso). Porque ele é um ser cosmológico, o animal é do lado da vida, enquanto que, na medida em que ele é um ser metafísico, o homem é eminentemente um ser vivo, o ser vivo por excelência, quer dizer, simplesmente, muito mais individuado ou realizado como ser vivo do que o animal (Barbaras, 2013a, p. 349-350).

O que significa que, do ponto de vista metafísico, a vida animal é a vida do homem menos alguma coisa, conforme Heidegger, antes criticado pela mesma ideia. Mas o que nos interessa é o conteúdo e não a letra da crítica ou do termo antropologia privativa.

Não tratamos propriamente, como dissemos, nem da cosmologia nem da metafísica em Barbaras, mas anunciamos que no ensaio já estava implícito o sentido de uma biologia também privativa, visto que não há Aberto sem mundo. A arquivida só é enquanto manifestação dinâmica do mundo, e nesse sentido o mundo e seu fundo, por definição é mais do que a percepção humana, por mais que esta se junte a ele por meio da arte e do amor, como desenvolvem as últimas obras de Barbaras (2016a, 2016b). É mais, mas, curiosamente, assim o é porque assim se mostra. Como destacamos, Barbaras usa às vezes a expressão Englobante (Barbaras, 2003, p. 122; 2011b, p. 200; 2016 b, p. 144) para apontar para esse além do mundo que jamais será presente, e a diferença com a fenomenologia é que Barbaras, ao contrário, por exemplo, de Merleau-Ponty (note-se, no fim da penúltima citação, o termo "obscuridade da arquivida"), dá nome a ele: de Vida ou Arquivida. E o faz destacando, mais do que Merleau-Ponty, o movimento que o "anima" ou é intrínseco à manifestação do mundo (Barbaras, 1999, p. 62; 2011b, p. 150-151; 152; 154; 2013a, p. 147-153).

Vamos especificar nossa questão de um ponto de vista fenomenológico, portanto, não cosmológico ou metafísico, para perguntar se não há, nessa passagem, certa ambiguidade na filosofia de Barbaras.

A saber, vimos que em sua filosofia o reconhecimento do mundo e do Aberto só é possível a partir da percepção da vida humana. Nos termos de Barbaras no ensaio, "O que equivale a dizer que o Aberto só existe enquanto tal, ou seja, reconhecido, quando ele já está perdido; e, pelo contrário, só atinge o Aberto quem não o reconhece de nenhuma maneira" (2011a, p. 170, grifos nossos). Ou ainda, "O mundo não é nada senão o Aberto: o próprio Aberto enquanto privado de sua plenitude, por ter sido reconhecido" (2011a, p. 170, grifo nosso).

Em outros termos, porque mais distante da arquivida do que a vida animal, o homem pode reconhecê-la do exílio. Dois traços fundamentais dessa separação são, conforme o próprio Barbaras (2016a), a temporalidade e a linguagem. Como ele diz, o signo é a presença da ausência (p. 149), que Barbaras, no entanto, marcando sua diferença com Lacan, evita tomar como seu "fato" fundador, melhor dizendo, arquifato. É disso que trata a metafísica de Barbaras, a saber, do evento ou acontecimento da privação (arquiacontecimento) de vida com o surgimento da humanidade. Sua cosmologia trata do arquimovimento que caracteriza a arquivida (ou Vida com maiúscula), e a metafísica trata do arquiacontecimento que caracteriza a privação dos seres vivos individuados dessa Vida. Nes- se sentido, abrindo um pequeno parêntese, encontra-se a posição decisiva de Barbaras (2013a, pp. 288-289) contra qualquer forma de idealismo da redução transcendental, que não reenvia a um sujeito, mas a um Fato transcendental e, portanto, não propriamente a um fato, visto que todo fato reenvia a uma essência, enquanto esse Fato é pura abertura para a experiência de fatos e essências, e daí a expressão Arquifato ou Fato com maiúscula.

No caso, pois, da sua diferença com Lacan, não é a linguagem que representa o "lugar" desse Fato, mas o desejo (2016a, p. 151), ou seja, a linguagem apoia-se na falta, antes que a falta se apoie na linguagem (significante).

E a temporalidade é a abertura ou o extravasamento do virtual no atual. Por isso Barbaras (2016a, p. 142) diz que o animal vive mais no espaço do que no tempo, ou que a vida animal é mais espacial que temporal. E o contrário com o homem, tal como mostra a experiência da linguagem, que se realiza estaticamente, ou cujo movimento se reduz à articulação da voz. Por isso a linguagem é expressão temporal da experiência de mundo (Barbaras, 2016a, p. 145). Ora, é justamente o tempo, pois, que abre o espaço humano (para além do atual) e a possibilidade de seu reconhecimento com a linguagem, que, como mostra Barbaras, pode levar tanto à sua objetivação, quanto ao Aberto do mundo, isto é, a habitá-lo poeticamente, na fórmula sintética de Hölderlin, explorada desde Heidegger e que Barbaras utiliza por meio da obra de Dufrenne (Barbaras, 2016a, em particular p. 174).

Mas, enquanto vinculamos na experiência humana de mundo a abertura do espaço à abertura do tempo, espaço de lonjuras que transborda o atual e que remete ao para além-mundo, Barbaras reafirma a tese metafísica e cosmológica da intencionalidade superior do animal sobre a intencionalidade humana, relativa ao espaço. Encerraremos nosso texto com ela. Referindo-se às "grandes migrações de pássaros, o andorinhão, por exemplo, podendo voar $4000 \mathrm{Km}$ sem pousar, assim como às distâncias imensas percorridas pelas enguias e pelos salmões para se reproduzir", ele completa:

Esses fenômenos são quase-cósmicos, como na fronteira do ser vivo e da physis, na verdade um tipo de afloramento da arquivida e de sua potência naquela dos seres vivos individuados. Aliás, sem dúvida não é sem importância que tais 'proezas' (de nosso ponto de vista) não sejam jamais o fato de indivíduos isolados, nem, aliás, de indivíduos muito individualizados, como se a condição dessa inscrição na superpotência cósmica fosse uma falta de individualidade, a persistência de uma dimensão pré-individual que se atesta no modo de existência e de deslocamento gregários. Por outro lado, essa vitalidade é indissociável de uma intimidade sensível com o mundo que excede em muito nossas próprias capacidades: os animais percebem a distâncias muito grandes, detectam quantidades ínfimas e seus deslocamentos pressupõem uma capacidade de orientação que é de dimensão cósmica. Não há nada de surpreendente nisso: sua potência perceptiva é como proporcionada à sua ausência de separação do mundo, ela exprime o primado do pertencimento sobre a distância (Barbaras, 2016a, p. 128). 
Ora, deixando os pássaros e os peixes de lado, mas nos apoiando na bela interpretação dessa passagem, perguntamos: poderíamos dizer que a arquivida tem uma percepção imediata de si, sem distância de sua dinâmica de manifestação de mundo ou realização cosmológica, enquanto o saber humano, esse do reconhecimento com o qual iniciamos nossa questão, é o saber possível e finito em regime de privação de vida? Assim se completa ou se elucidaria a ideia do ensaio, de que a vida "é caracterizada por uma abertura à transcendência, cujo alcance excede muito o da percepção humana” (2011a, p. 165), ou, “em outras palavras, se a consciência é intencional, é primeiro porque a própria vida é intencional, num sentido mais profundo e mais radical, de modo que a dimensão objetivante da consciência propriamente dita deve advir de uma forma de limitação dessa abertura originária” (2011a, p. 166).

Dito de outra forma, se a percepção animal do mundo é superior à percepção humana, porque mais próximo da Vida (arquivida), a arquivida teria de si uma percepção sem distância ou um Sentir imanente à sua própria manifestação?

Se entendemos bem, Barbaras não dá esse passo, mas perguntamos se, assim, chamar de vida o arquimovimento da manifestação que nos antecede (a physis) não corre o risco de ser mais um uso retórico do conceito de vida, conforme Barbaras acusa a fenomenologia no início do ensaio (2011a). Ou seja, tem sentido falar de vida sem uma sensibilidade originária inscrita em seu próprio ser?

Barbaras (2016a) chama de Sentimento o pathos originário da vida individuada em sua privação de Vida (arquivida). O que significa que o Sentimento é tanto o testemunho do pertencimento dos seres vivos à Vida de onde nasceram, quanto de sua privação; o Sentimento é a presença da vida em nós em nosso estado de privação de vida. Como presença, Barbaras o chama de contra-acontecimento (o acontecimento da privação de que trata a sua metafísica, que representa o nascimento dos seres vivos no mundo). Mas a perspectiva que queremos destacar, aqui, não é o caráter da privação (todo sentimento é nostálgico, como ele diz, 2016b, p. 177), e sim o caráter do pertencimento, que representa, se entendemos bem, o caráter sensível da vida, em comunidade, pois, com o sensível da manifestação do mundo. Por isso ele vai dizer que o desejo de mundo ou de outra vida se guia pelo sentimento (Barbaras, 2016b, pp. 182-183).

Voltando, então, ao ponto de nossa questão, notamos que Barbaras (2011b, p. 152) chega a afirmar a relação do mundo com o fundo como a estrutura dinâmica da arquivida. Ora, essa relação é uma hiperpercepção da vida por si mesma? Uma "coincidência intuitiva" (2013a, p. 348) ${ }^{12}$, inscrita em seu próprio dinamismo? E, se não é assim, tem sentido pleno chamar de vida tal arquimovimento de manifestação do mundo?

Mais do que avançar nessa direção, nossa intenção é nuançar o termo Vida para a expressão do arquimovimento ou da physis, na filosofia de Re-

12 Barbaras usa o termo contrastando o conhecimento humano, que "não é plenitude, mas falta", com o que seria a intencionalidade da vida animal (2013a, p. 347-348). naud Barbaras, ou, antes, acentuar o mistério do Fundo da manifestação do mundo e de nossas vidas.

\section{Referências}

Barbaras, R. (1999). Le désir et la distance, Introduction à une phénoménologie de la perception. Paris: Vrin.

Barbaras, R. (2003). Vie et intentionnalité, Recherches phénoménologiques. Paris: Vrin.

Barbaras, R. (2008). Introduction à une phénoménologie de la vie. Paris: Vrin.

Barbaras, R. (2011a). "Vida e consciência”, In Investigações fenomenológicas, em direção a uma fenomenologia da vida (pp. 163-177). Curitiba: UFPR.

Barbaras, R. (2011b). La vie lacunaire. Paris: Vrin.

Barbaras, R. (2011c). “A presença do filósofo”, In Investigações fenomenológicas, em direção a uma fenomenologia da vida (p. 233-245). Curitiba: UFPR.

Barbaras, R. (2011d). "A fenomenologia da vida e o problema da intencionalidade", in Investigações fenomenológicas, em direção a uma fenomenologia da vida (pp. 179-193). Curitiba: UFPR.

Barbaras. R. (2012a). "Dinâmica da manifestação", Cadernos espinosanos n. XXVII, p. 11-29. São Paulo: USP.

Barbaras, R. (2013a). Dynamique de la manifestation. Paris: Vrin.

Barbaras, R. (2013b). Vers une biologie privative. Réponse à Pierre Rodrigo. Alter, Revue de phénoménologie, n. 21, pp. 267-275. Dijon: Alter.

Barbaras, R. (2016a). Métaphysique du sentiment. Paris: Cerf.

Barbaras, R. (2016b). Le désir et le monde. Paris: Hermann.

Jonas, H. (2004). O princípio vida, fundamentos para uma biologia filosófica. Tradução Carlos Almeida Pereira. Petrópolis, RJ: Vozes.

Merleau-Ponty, M. (2002). La structure du comportement, 2. ed. Paris: PUF (Originalmente publicado em 1942).

Merleau-Ponty, M. (1994). Fenomenologia da Percepção. Trad. Carlos Alberto Ribeiro de Moura. São Paulo: Martins Fontes. (Originalmente publicado em 1945).

Merleau-Ponty (2000). A natureza - notas de cursos no Collège de France, 1956- 1960 (texto estabelecido e anotado por Dominique Séglard - Trad. Álvaro Cabral). São Paulo, Martins Fontes.

Merleau-Ponty, M. (1996). Notes de cours, 1959-1961. Paris: Gallimard. 
Moutinho, L. D. (2012). De Merleau-Ponty a Barbaras. Cadernos espinosanos n. XXVII, pp. 63-70. São Paulo: USP.

Prado Júnior, B. (1988). Presença e campo transcendental: consciência e negatividade na filosofia de Bergson. São Paulo: Edusp.

Pinto, D. M. (2012). "A vida entre desejo e criação: Renaud Barbaras leitor crítico de Bergson", Cadernos espinosanos n. XXVII, pp. 31-61. São Paulo: USP.

Riquier, C. (2009). À la lisière du monde: La vie selon Barbaras. Critique, n. 750, pp. 981-993. Paris: Éditions de Minuit.

Riquier, C. (2013). La vie au cœur de la phénoménologie française. Alter, Revue de phénoménologie, n. 21, pp. 223-237. Dijon: Alter.

Sacrini, M. (2012). Renaud Barbaras, leitor de Husserl, Cadernos espinosanos n. XXVII, pp. 95-103. São Paulo: USP.

Veríssimo, D. S. (2013). A dimensão pulsional do sensível: elaborações acerca da percepção em Renaud Barbaras, Psicologia USP, n. 24(3), p. 489-507.

Reinaldo Furlan é Doutor em Filosofia pela Universidade Estadual de Campinas. É Livre Docente pela Faculdade de Filosofia, Ciências e Letras de Ribeirão Preto - USP, e Professor de Filosofia no Curso de Psicologia, pela mesma instituição. Realizou Estágio de Pós-Doutorado na França, sob supervisão de Etienne Bimbenet (Apoio FAPESP). Além de artigos publicados em periódicos nacionais, publicou capítulos de livros na área de fenomenologia: Merleau-Ponty e a psicossociologia (2017), O erotismo na filosofia de Merleau-Ponty (2016), Fenomenologia da vida contemporânea: a carne do mundo (2015), Da existência ao desejo da carne: ontologia em Merleau-Ponty (2012), Filosofia como 'pensamento de contato' (2006), entre outros trabalhos. E-mail: reinaldof@ffclrp.usp.br

Recebido em 20.03.2018

Aceito em 19.12.2018 